\title{
SOME INEQUALITIES FOR OPERATOR MEANS AND HADAMARD PRODUCT
}

\section{Jaguit Singh Matharu and Jaspal Singh Aujla}

Abstract. We prove some general theorems which unify results on arithmetic-geometric mean and some other related matrix inequalities. As an application we obtain some results involving Hadamard product of matrices.

Mathematics subject classification (2010): 47A30 15A60.

Keywords and phrases: Hadamard product, Operator mean, Tensor product.

\section{REFERENCES}

[1] W. N. Anderson JR. And R. J. Duffin, Series and parallel addition of matrices, J. Math. Anal. Appl., 26 (1969), 576-594.

[2] T. ANDO, Topics on operator inequalities, Lecture notes, Hokkaido University, Sapporo, 1978.

[3] J. S. Aujla AND H. L. VAsudeva, Inequalities involving Hadamard product and operator means, Math. Japon., 42 (1995), 265-272.

[4] R. B. BAPAT AND M. K. Kwong, A generalization of $A \circ A^{-1} \geqslant I$, Linear Algebra Appl., 93 (1987), $107-112$

[5] R. Bhatia And F. KitTAneh, Notes on matrix arithmetic-geometric mean inequalities, Linear Algebra Appl., 308 (2000), 203-211.

[6] J. E. CoHEN, Spectral inequalities for matrix exponentials, Linear Algebra Appl., 111 (1988), 25-28.

[7] M. FIEDLER, Über eine ungleichung für positiv definite matrizen, Math. Nachrichten, 23 (1961), $197-$ 199.

[8] F. Kubo And T. Ando, Means of positive linear operators, Math. Ann., 246 (1980), 205-224.

[9] B. MOND AND J. E. PEČARIĆ, A mixed arithmetic-mean-harmonic-mean matrix inequality, Linear Algebra Appl., 237 (1996), 449-454.

[10] K. Nishio AND T. ANDo, Characterization of operations derived from network connections, J. Math. Anal. Appl., 53 (1976), 539-549.

[11] W. PUSZ AND S. L. WORONOWICZ, Functional calculus for sesquilinear forms and the purification map, Rep. Math. Phys., 8 (1975), 159-170.

[12] S. WADA, On some refinement of the Cauchy-Schwarz inequality, Linear Algebra Appl., 420 (2007), 433-440. 